Brit. J. prev. soc. Med. (1974), 28, 191-195

\title{
Programmes, priorities, and budgets*
}

\author{
J. D. POLE \\ Department of Health and Social Security, London
}

Because health care in Britain is provided in the main by the National Health Service, the allocation of resources is determined to a relatively large extent by administrative mechanisms, guided by professional judgments, and to a relatively small extent by the mechanisms of the market. When I say 'relatively', the comparison implied is with countries where fee-for-service or a system of voluntary private insurance prevails; but it is surely the case in these countries also that the influence of the market is more attenuated in the health care services than it is in other sectors of the economy. Thus, while the problem of priorities is to a special degree public property in this country, it is not exclusive to us.

But although the provision of health care in Britain has been effectively socialized for 25 years, the Department of Health and Social Security has taken a rather cautious line about developing machinery for planning the allocation of resources. Partly perhaps from fear of offending the professions, and partly from a more robust British tradition of 'trusting the man on the spot', it has confined itself to distributing, admittedly not in equal quantities, money and good advice.

But it is clear from the White Paper on the Reorganization of the National Health Service, from the reorganization of the Department itself with client group-orientated divisions, from the development of a new costing system (Planned Programme Budgeting (PPB) and Programme Analysis Review (PAR)), and even from the employment of economists and operational researchers that it sees its role as resource planner in a more positive light in future.

It will be more systematic in its acquisition, presentation, and use of information, an attempt will be made to see that plans formed at different levels are consistent with each other, and sectoral plans will have to be coordinated with or traded off against each other through a formal planning mechanism.
The problems of planning in the health and personal social services seem to me to be of two main kinds: first, what kind of planning is feasible in a system which is subject to such a high degree of decentralization not only geographically but also in terms of the multiplicity and complex interrelation of decision makers, among whom professionals claim particular prerogatives; and, secondly, what sorts of information can we get and how much is it worth trying to get?

The accounting system in the public sector has gone through a slow but fairly radical evolution since the time of the Gladstonian preoccupation with saving candle-ends. Since 1948 the National Health Service has gone through two-and-a-half stages of the evolutionary process. The first stage, described by Montacute, lasted until about 1957; the principle involved was that of traditional subjective accounting-so much for wages and salaries, so much for heat, light, and power, and so forth. This form of account is valuable mainly for audit purposes; it does not give much information which is useful for management, because it gives no idea what the people concerned, or the heat, light, and power, are actually doing.

In the next stage of evolution this was recognized, and a more functional system was introduced. This is the system which has operated up to the present; the accounts are analysed by cost-centres, such as wards, laundries, pharmacy, etc. This is a considerable improvement from the managerial point of view because, for example, it enables comparisons to be made between the costs of different hospitals at departmental level.

But of course it gives no idea how much of the nursing, linen, or drugs is being used for caring for, say, the mentally handicapped. One should not exaggerate this problem. Hospitals are of different types (19 at the last count) so that one can get some impression of what is going on, and how much it is

*Presented to an Advanced Seminar on Health Economics at the Centre for Extension Training in Community Medicine, London School of Hygiene and Tropical Medicine, 1-3 November 1973 
costing, at least for some sorts of conditions. It is only for acute kinds of care that one has very little idea from the costing returns as such. Even there one can achieve some approximation by studying the figures on bed utilization so lavishly provided by the Hospital In-Patient Enquiry, provided one is prepared to guess how the cost of a bed-day occupied by a patient with one condition compares with that of a bed-day occupied by a patient with another. But there is relatively little information on the costs of services outside hospital by types of patient. The new costing system, which is now under trial, goes some way towards costing the service in terms of the kind of cases it is treating. There will be a primary analysis to departments (or cost centres); a secondary analysis of most departments to inpatients, outpatients, and day patients; and a tertiary analysis (for inpatients only) to groups of specialties of the costs of departments providing services directly related to patient care.

The number of specialty group categories envisaged is not very large at present, but presumably it can be increased if the system turns out to be practical and useful. There is bound to be a certain amount of arbitrariness about the apportionment of some types of costs between activities, and there is the question how much it is worth spending in order to achieve accuracy. There are also bound to be a certain number of definitional problems. Conditions which are treated by a geriatrician in one hospital are treated by a general physician in another, and so on. It is also true that the system is based on the old hospital costing system, and there are major differences of philosophy and tradition between the hospital service and the community-based services, but although bridging the gap presents difficulties, the community services have been brought into the system of accounts.

The new accounting system is not yet operational. Even when it is it will not give all the information required, though it will facilitate its acquisition; but the Department is now committed to a system of planning including a programme budget. Budgets have been prepared for current and several past years as a basis for considering further policy development.

There were probably two main strands of causation which led the Department, after 20 years without any, to employ economists on the study of health and health services. One was the increasing awareness of some senior doctors in the Department of the potential costliness of various impending developments, such as mass screening programmes, which were in vogue at that time. The other was the decision of the Department to go in for programme budgeting.
The philosophy of PPB, as it was developed in the United States, was based on the assumed tendency for the activities of bureaucracies to acquire a momentum of their own, and progressively to lose their orientation towards the objects they were instituted to pursue. PPB drew a distinction between activities, the mere crackling of thorns under the pot, and programmes, the contents of the stew. The essential aim of PPB was to specify programmes, each of which should contribute to some well-defined objective, with a view to comparing their costs and effectiveness. Only by identifying objectives would it be possible to make sense of the activities of the organization, while in order to evaluate these activities they must be organized into programmes.

The pure theory of PPB (if anything so empirical can be said to aspire to a pure theory) laid great stress on the definition of objectives and the tying of programmes to objectives, but a too-philosophical approach can lead to absurdities. Having a broken leg mended enables the patient to fulfil a variety of personal or social objectives, such as earning a living, playing football, enjoying the society of his wife and children, etc., but it would be absurd to allocate the costs of mending the leg between several programmes each orientated towards some such objective.

As a basic component of the Departmental planning system programme budgeting clearly has many aspects which are not relevant to my theme, even if there were time to discuss them. In what follows I wish to concentrate on the use of the programme budget or similar accounting-based information for purposes of evaluation.

From this point of view the programme structure should, in my view, be mainly determined by the decisions to the taking of which one wishes it to contribute, and this brings us back to the question of what sort of decisions can and should be taken at what levels. As an hypothesis, one might suggest that where decisions are primarily a matter of political or moral judgment-of determining basic priorities, one would want the activities to be compared to reside in different programmes-the mentally handicapped against the alcoholics; but where it is a more technical question of how particular objectives can best be achieved-drug therapy against behavioural therapy-one would want the activities to be compared to be within a particular programme. This distinction ties up with an economic jargon of a slightly older vintage-that of cost-benefit and cost-effectiveness; and through that to the main stream of neoclassical welfare economics, which attempts to make a distinction between the choice of the composition of the basket of outputs and the choice of the set of resources from 
which each output is to be produced. The former is, in a broad sense, a question of tastes, values, or utilities; the latter is a question of techniques.

In practice, it is not easy to make a hard and fast distinction between technical matters and matters of values or utilities in the Health Service. From one point of view the question whether to treat schizophrenics in hospital or in the community is a technical one. Which is the cheaper way to fulfil whatever are the society's requirements for the treatment of this group? But community care originally became fashionable as a good thing in itself. The practitioners are very apt to muddle the medical and economic arguments when it suits them, and the politicians and administrators equally so when it suits them, but the economist's concern is to keep them separate. It is not easy to design an accounting framework which succeeds in doing so, but at least it may be useful to have the idea in mind.

A major complication is the fact that some programmes ought really to cover the personal social services as well as the Health Service. Social workers tend to take a broader view than doctors: they deal in syndromes. Even when there is a well-defined task for the personal social services, the objectives of care as seen by the social worker or other social services professional may be quite different from those perceived by a doctor considering the same case. On the whole, the objectives of medical care fall into reasonably well-defined traditional categoriespreventing mortality, morbidity, disability, painbut those of the personal social services are vaguer or perhaps more subtle.

Apart from acute care, which is essentially a medical phenomenon, the solution adopted so far is to distinguish client groups characterized either by their medical condition-mental illness or handicap, physical disability, maternity, dentistry, etc. - or by some broader social characteristic - the elderly, problems of children and families, etc. Although this twofold system of classification leads in principle to numerous ambiguities, in practice the resolution of these difficulties may not involve too much arbitrariness.

But what is the value of these analyses from a policy point of view? How far do they help us to make better judgments of priorities for the health and personal social services?

It seems obvious that if the Minister has only the vaguest notion how much of his Department's total budget is being devoted to what, further information on the subject is bound to do some good. But the programme budget is basically only an account of expenditure, analysed by output-orientated categories. In some cases the mere revelation of the orders of magnitude of expenditure on various programmes may by itself give clear indications of priorities for expenditure, but it cannot be relied upon to do so. Can we go further and reduce the area of judgment by the use of some explicit method of evaluation?

In order to arrange the spending of money optimally, it would be necessary to know not only the cost of each activity but also its effectiveness. The problems are formidable.

So far as the cost side is concerned, each programme comprises a heterogeneous collection of activities, and one cannot sensibly use an index to measure the cost of such a collection: changes in the proportions between the activities are what one is interested in. One would have to measure cost activity by activity, and that would be a rather tall order as the number of activities included in, say, a surgical or medical programme, even when defined in a patient-orientated way as complete treatments, is very large. In fact those who have tried it even question whether it is possible to specify a sufficiently small number of treatments for each diagnostic category to make it meaningful to speak of a cost for that category. At the other extreme one can go to a full system of patient costing, perhaps as an extension of Hospital Activity Analysis (HAA). But there is a question of cost-effectiveness, and also a data-handling problem, for such a mass of information. There is no simple basis of aggregation. Apart from the question what units of activity are to be costed, there is also the difficulty that what we need are marginal costs rather than average costs. According to theory, whether marginal costs are equal to average costs or larger or smaller depends on whether the size of the operating units is just right, or too big, or too small, but, in spite of a good deal of effort, there is still considerable doubt about, for example, the technically optimal size of a general hospital.

When the Department of Education and Science attempted their first programme budget they firmly embraced the marginal principle. The total budget was broken down into a sum which would be necessary to keep things going on as they are at present in the various age groups, and additional sums which would be required for various changes in the quantity or quality of output.

This may work quite well in education, but I doubt whether it is the right approach for health and the personal social services. Educational planning is comparatively straightforward because people progress through the system in an orderly manner and do not switch about in a random way between nursery school and university. The number of policy options is also limited to some extent because the 
system is administered through the local authorities who have autonomy except in matters of the broadest strategic kind; for one reason or another the policy options seem to be fairly clearly distinguished over the medium term. It may make sense to present a programme budget as a set of costed options.

But in the health and personal social services there are so many options, and they may change so quickly from year to year, that no routine costing system can express a set of marginal costs which embraces all the relevant dimensions of change. There must be costed options at any given date, but these should, in my view, be based on or derived from the programme budget rather than being part of it. The programme budget should frankly be a set of accounts which one hopes may be both suggestive in itself and a basis for further analysis, including analysis of marginal costs.

This issue of the character of the programme budget comes out fairly clearly in the case of capital. In the Departmental accounting and budgeting system a great deal of effort is devoted to analysing the use of new capital and the consequences of its use for subsequent revenue expenditure. It is really a capital budgeting approach, and corresponds quite well at first sight with the economist's notion that once capital is sunk in a particular form it ceases to be an economic cost. One is only interested in the marginal capital cost of increases in output for comparison with their marginal benefits. But we are still a long way from measuring all or even many of the marginal costs and benefits. We are still in the age of political and professional judgment. It is still hot news that we are spending $\mathrm{fx}$ millions on maternity services and fy millions on orthopaedicsin revenue terms. In these circumstances it seems to me to be premature to dismiss the idea of measuring in some way-no doubt an accountant's way-the value of the existing capital.

There are two particular reasons why this may be important. First, the increment of capital is quite small compared with the stock-we may be barely holding our own at present in 'maintaining capital intact' - so that the transfer and user cost of capital for maternity or orthopaedics may be an important planning concept, though not one the Department has paid much attention to up to now; and, secondly, the improvements which new capital investment brings about are mainly improvements in quality rather than increases in quantity. This suggests that it may be particularly difficult to measure the marginal benefits of investment, while some idea of annuity value of the flow of services to particular programmes from existing capital may be illuminating if one is trying to assess the relative claims of each programme for more.

On the benefit side things are even more difficult. There are really two problems. The first is that we have no index of benefit, although tentative steps are now being made in various quarters towards devising one. Although the medical categories of mortality, morbidity, etc. are well established, we have only the vaguest and most contradictory indications of the trade-offs between them. But even if we did have a well-defined index of medical output, we should still be at a loss, because we generally have very little idea how a particular medical treatment would move the index, if at all, since we do not know the effectiveness of many forms of medical treatment even in purely medical terms.

It is encouraging that some doctors are interesting themselves in the measurement of the output of medical services, with regard both to devising synthetic measures of output and to measuring empirically the outcome of treatment in more conventional terms; but there is clearly an immense distance to go, and there must be a danger of committing ourselves prematurely to a view of the priorities problem which is incapable of realizatios within a tolerable periods.

There is, in fact, a dilemma. The problem of priorities is most meaningful on the large scale-it does carry conviction to discuss the priority to be accorded to hospital confinement, to preventing hypothermia in the elderly, or to improving the lot of some mentally handicapped children and their nurses. It may not make so much sense to discuss the relative priorities to be accorded to specific conditions within an acute hospital, or even within an acute specialty, because these problems are not yet settled at the Department of Health and Social Security or even by the Regional Board.

Effectively, they lie within the prerogative of the admitting consultant or his registrar and their peer group within the hospital. But the devising of a scale of measurement for the benefits from reducing the hazards of childbirth, or preventing hypothermia, or from improving the condition of mentally handicapped children is fraught with difficulty, while integrating into a single scale these highly disparate kinds of benefit would call for judgment of a heroic kind. Perhaps only a politician could rise to such a judgment, and politicians never answer hypothetical questions. This is the kind of difficulty, I suspect, which has deterred the Department from too active a planning role in the past.

.
(n) ஸ) $\overrightarrow{0}$ 号 0 $\frac{0}{0}$ 
We shall, of course, continue to try to develop our analytical capacity and carry out cost-benefit studies of various proposals which arise from time to time, and the Department will continue to form a judgment, based on a professional opinion, financial stringency, and the various pressures which bear on it, as to whether each proposal is something to support or not, or how far. But such ad hoc exercises will, I suspect, increasingly come to be seen in the context of an overall system of priorities, and the programme structure and the programme budget will act as a focal point.

The author is a Senior Economic Adviser at the Department of Health and Social Security, 151 Great Titchfield Street, London W1P 8AD. The views expressed are his own and not those of the Department. Published by permission of the Controller of Her Majesty's Stationery Office. 